\title{
Aprendizagem ao longo da vida: entre a novidade e a reprodução de velhas desigualdades
}

Mariana Gaio Alves

Universidade Nova de Lisboa, Portugal

Resumo

A apologia da aprendizagem ao longo da vida, designadamente ao nível dos discursos políticos da Comissão Europeia, parece traduzir a crença de que se trata de uma nova orientação estratégica que permitirá solucionar muitos dos velhos problemas que se vêm colocando aos sistemas de educação e formação. Neste artigo, pretende-se debater em que medida a aprendizagem ao longo da vida corresponde, de facto, a uma novidade no campo educativo. Para tal consideramos, de modo articulado, três dimensões de análise: discutimos os sentidos e significados que lhe são atribuídos, reflectimos sobre as eventuais alterações que introduz, por um lado, nas orientações estratégicas subjacentes às políticas educativas e, por outro lado, nos processos de educação e formação. Procura-se, também, indagar de que modo a promoção de dinâmicas de aprendizagem ao longo da vida permite atenuar (ou não) as desigualdades que têm marcado o desenvolvimento dos sistemas educativos.

Palavras-chave

Políticas Educativas Europeias; Desigualdades; Aprendizagem

\section{Nota Introdutória}

A educação tem sido, desde a emergência dos sistemas educativos, objecto de grandes expectativas e investimentos por parte dos indivíduos 
isoladamente considerados e das sociedades e estados nacionais enquanto entidades colectivas. Da educação se espera que contribua para a promoção da igualdade de oportunidades, do crescimento económico, do desenvolvimento humano, do progresso, da cidadania, da empregabilidade, da qualidade de vida, da coesão social, entre muitas outras finalidades.

$\mathrm{Na}$ actualidade, a importância da educação nos modelos de desenvolvimento económico, social e humano não diminuiu, num contexto em que a ideia de aprendizagem ao longo da vida assume grande centralidade e é objecto de grandes debates, designadamente no contexto europeu, reforçando a relevância atribuída ao sector educativo nas sociedades contemporâneas e nas políticas educativas actuais.

Neste artigo, analisamos em que medida a ideia de aprendizagem ao longo da vida corresponde, de facto, a uma novidade no campo educativo, mobilizando contributos teóricos e conceptuais, bem como informação empírica proveniente quer de análise de documentos da União Europeia centrados na aprendizagem ao longo da vida e respectivas "competênciaschave", quer de indicadores estatísticos disponibilizados pelos organismos europeus ${ }^{1}$.

\section{Aprendizagem ao Longo da Vida e Políticas Educativas Europeias}

A centralidade crescente da ideia de aprendizagem ao longo da vida nas políticas educativas europeias conduz a que alguns autores se interroguem sobre até que ponto estaremos a assistir à emergência de uma "era de Aprendizagem ao Longo da Vida" que contrasta com uma "era de Educação" que poderá estar em claro declínio (Tuschling \& Engemann, 2006). Com efeito, "o protagonismo conceptual e a apologia actualmente registados pelas ideias de formação ao longo da vida e, especialmente, de aprendizagem ao longo da vida, não têm precedentes na história das políticas educativas e, em geral, das políticas sociais" (Lima, 2003: 130).

Noutros termos, o que queremos sublinhar é que, ao nível dos discursos políticos, a ideia de aprendizagem ao longo da vida parece ser, de facto, uma novidade recente. Em nosso entender, é aliás possível colocar a hipótese de que esta ideia constitua, de algum modo, um novo princípio 
estruturante do sector educativo, pelo menos no plano do discurso e da retórica.

A emergência da aprendizagem ao longo da vida como ideia central dos discursos e políticas educativas - ou seja como conteúdo das agendas políticas - é coincidente com a intensificação do papel da União Europeia na área das políticas educativas. Tal intensificação vem-se sentindo desde o ano 2000 na sequência do Conselho Europeu de Lisboa no qual se estabelece uma nova visão estratégica - "tornar a União Europeia a sociedade do conhecimento mais competitiva e dinâmica, capaz de enfrentar o crescimento económico com melhores empregos e uma maior coesão social" (Estratégia de Lisboa, Conselho Europeu, 2000) - que só pode ser alcançada mediante o investimento significativo no sector educativo/formativo.

Nestas condições,

o momento que actualmente vivemos parece constituir uma fase inédita (...) as dinâmicas de europeização e de constituição de um referencial global europeu para as políticas educativas (...) assumem, hoje (...) uma intensidade, uma amplitude e profundidade de intervenção claramente distantes daquelas que ocorriam há apenas uma década atrás (Antunes, 2005: 137).

Para outro autor (Nóvoa, 2005), numa perspectiva convergente, a fase actual de influência da União Europeia nas políticas educativas inicia-se com a Cimeira de Lisboa do ano 2000 e pode ser apelidada de "política em estado sólido", no sentido em que se traduz no estabelecimento de diferentes programas de acção que pretendem, claramente, influenciar as políticas educativas dos Estados-Membro na área da educação. Anteriormente, de acordo com o mesmo autor (Nóvoa, 2005), as fases de "política em estado líquido" e "política em estado gasoso" distinguem-se pelo marco que constitui o Tratado de Maastricht em 1992, pois antes deste as possibilidades de acção da Comissão Europeia em matéria de educação/formação eram bastante reduzidas e, após o Tratado, assiste-se a um discurso recorrente sobre a dimensão europeia de educação e acentua-se a produção de numerosos documentos (do tipo livros verdes e brancos e declarações) sem consequências imediatas, mas influentes na evolução política europeia em matéria de educação.

Assim sendo, constata-se que ao surgir como o principal lema das políticas educativas europeias no início do século $X X I$, a ideia de 
aprendizagem ao longo da vida está presente nas orientações estratégicas para a área da educação/formação nos diversos Estados-Membro. Ainda que a acção política europeia não se organize em torno de sanções e imposições aos diferentes Estados, verifica-se que através da discussão e construção partilhada de diagnósticos, recomendações e planos de intervenção, as orientações europeias acabam por se constituir como referentes incontornáveis para cada um desses Estados. Como afirma Nóvoa (2005: 214), a "retórica de Bruxelas sublinha sistematicamente a ideia de que «é preciso aprendermos uns com os outros", favorecendo a melhoria das políticas nacionais no que respeita aos objectivos definidos em comum". Face a esta recorrência dos discursos políticos em torno da aprendizagem ao longo da vida, procuramos seguidamente explicitar os sentidos e significados que Ihe podem ser atribuídos.

\section{Sentidos e Significados de Aprendizagem ao Longo da Vida}

Como todas as ideias com uma ampla difusão e generalização, a ideia de aprendizagem ao longo da vida arrisca tornar-se um conceito polissémico e relativamente opaco que recobre uma multiplicidade de sentidos e significados nem sempre claros e explícitos, pelo que consideramos necessário procurar clarificar quais os fenómenos e situações que engloba e quais os entendimentos, muitas vezes plurais, que encerra.

Assim, importa destacar desde logo que a centralidade crescente da ideia de aprendizagem ao longo da vida tem vindo, em nosso entender, a originar uma re-actualização dos debates e concepções correntes sobre processos de educação e aprendizagem. Na verdade, introduzindo uma perspectiva histórica, podemos identificar desde a Antiguidade Grega e Romana (ver, por exemplo, Fernández, 2006) referências a pensadores que encararam os processos educativos deste modo abrangente, simultaneamente, do ponto de vista dos tempos e espaços em que se aprende. É que "nunca a aprendizagem se reduziu à idade inicial do ser humano. Ainda que na nossa história mais recente se tenha identificado a figura social do estudante com o sector da população juvenil, isto nem sempre foi assim e certamente voltou a deixar de sê-lo, de uma maneira definitiva, na sociedade do século XXI", como sublinha Fernández (2006: 7). 
Com efeito, consideramos que a emergência, desenvolvimento e consolidação dos sistemas educativos durante os séculos XIX e XX contribuiram para a difusão de uma visão escolarizada em que se associa estreitamente aprendizagem e processos desenvolvidos no interior dos sistemas educativos. Concomitantemente, ao "transformar a educação em refém da forma escolar" (Canário, 2003: 203) desvaloriza-se a noção de que a aprendizagem pode corresponder a "toda a oportunidade existente em qualquer instituição social para um indivíduo adquirir conhecimento, 'skills', atitudes, valores, emoções e crenças no quadro da sociedade global, bem como o processo pelo qual cada indivíduo os adquire" (Jarvis, 2007: 99).

Ora, a ideia de aprendizagem ao longo da vida, entendida como um processo que acontece em diversas fases do ciclo de vida dos indivíduos e nos diferentes espaços da sua existência, significa, justamente, (re)alargar o âmbito dos conceitos de educação e aprendizagem, reconhecendo a relevância de espaços e tempos educativos que estão para além dos espaços e tempos escolares. Trata-se, afinal, de retomar uma tradição que incorpora, designadamente, o Relatório Fauré publicado pela UNESCO em 1972, que remetia para os ideais da Educação Permanente e que foi considerado um ponto de viragem no modo como se concebem os processos educativos (Canário, 2003; Lima, 2003; Biesta, 2006). Este documento dava grande relevo à ideia de que o processo educativo é coincidente com o ciclo de vida dos indivíduos, sendo a construção da pessoa uma dimensão essencial desse processo numa visão que alguns designam de existencialista (Jarvis, 2007).

Noutros termos, o que pretendemos evidenciar é que a ideia de aprendizagem ao longo da vida, entendida desta forma alargada em que abrange todos os espaços e tempos da vida do indivíduo, não constitui então uma novidade recente, embora a sua mobilização como lema e elemento estruturante das políticas constitua um elemento novo no contexto educativo.

No entanto, importa sublinhar que a ampla difusão da ideia de aprendizagem ao longo da vida pode, a nosso ver, encerrar alguns riscos associados a entendimentos redutores do termo. Um desses entendimentos é redutor porque a aprendizagem ao longo da vida é vista enquanto educação de adultos, como de resto está subjacente aos indicadores estatísticos (como por exemplo os disponibilizados pelo Eurostat) que a medem através da participação de adultos em acções de educação/formação. Um outro 
entendimento redutor traduz-se na estreita associação entre aprendizagem ao longo da vida e sistemas educativos, esquecendo que a aprendizagem decorre também em espaços informais que não se estruturam em termos de objectivos educativos e que correspondem às actividades diárias relacionadas, designadamente, com o trabalho, a família ou o lazer ${ }^{2}$.

A estes sentidos restritivos da ideia de aprendizagem ao longo da vida acrescem, pelo menos, dois grandes riscos de reducionismo no modo como esta ideia se tem tornado um elemento central das políticas educativas europeias, os quais diversos autores (ver, por exemplo, Biesta, 2005 e 2006; Nóvoa, 2005; Canário, 2003; Lima, 2003) têm vindo a evidenciar, contribuindo para uma reflexão crítica sobre a difusão e generalização da ideia de aprendizagem ao longo da vida.

Um desses riscos consiste em subjugar a aprendizagem ao longo da vida a finalidades profissionais e de competitividade económica, reduzindo os processos de aprendizagem dos indivíduos a meios para assegurar a capacidade produtiva de cada um de nós. Neste sentido, Biesta (2006) argumenta que a União Europeia tem uma visão claramente economicista da aprendizagem ao longo da vida ${ }^{3}$, reduzindo-a à sua função de "serviço ao emprego e à economia", enquanto Lima (2003: 129) afirma que "hoje, porém, o apelo sistemático à formação e à aprendizagem tende a ser predominantemente orientado para a adaptabilidade, a empregabilidade e a produção de vantagens competitivas no mercado global".

Um outro risco de reducionismo, no modo como a ideia de aprendizagem ao longo da vida tem sido mobilizada enquanto elemento central das políticas educativas europeias, encontra-se no facto de a mesma tender a ser entendida, sobretudo, como um processo que é responsabilidade exclusiva dos indivíduos. Nas palavras de Nóvoa (2005: 218), faz-se "o elogio do aprendente 'responsável' e 'sensato', criticando simultaneamente aqueles que não são capazes de tomar conta da sua própria vida, ou seja da sua própria formação". Nos termos de Biesta (2006), trata-se de considerar a aprendizagem como um assunto e uma responsabilidade do indivíduo, menorizando a necessidade de criar condições que favoreçam a emergência de dinâmicas de aprendizagem ao longo da vida e a adesão dos indivíduos a essas dinâmicas. Essas condições, favoráveis à aprendizagem ao longo da vida, passam por uma multiplicidade de estratégias como sejam as 
oportunidades educativas e formativas dirigidas a diferentes tipos de públicos, os mecanismos de reconhecimento e validação de aprendizagens informais, os apoios concedidos aos indivíduos (financeiros, mas também logísticos) para frequentar acções de educação e formação, entre outras.

\section{Aprendizagem ao Longo da Vida nos Documentos da União Europeia}

Com o objectivo genérico de compreender os sentidos e significados conferidos à aprendizagem ao longo da vida nas orientações estratégicas da política educativa europeia, apresentam-se, em seguida, alguns resultados da análise documental realizada (corpus de 20 "textos políticos"4). 0 corpus de 20 documentos que analisámos está dividido em dois grupos ${ }^{5}$ : o conjunto A é constituído por 12 documentos de enquadramento político genérico da Comissão Europeia na área da educação/formação, enquanto o conjunto B é composto por 8 documentos que dão conta da actividade de um grupo de trabalho centrado nas competências-chave da aprendizagem ao longo da vida. Procuraremos sistematizar os resultados da análise destes documentos em torno de algumas ideias-chave.

Uma dessas ideias-chave corresponde a um debate que se centra no questionamento das implicações de uma aparente alteração de linguagem, em que os vocábulos educação ou formação parecem estar sendo substituídos pela expressão aprendizagem (Biesta, 2005). Sobre esta matéria gostaríamos de sublinhar que a análise quantitativa dos termos "educação", "formação" e "aprendizagem" (e outros adjacentes como educar ou aprender, por exemplo) não nos permite, em qualquer dos dois conjuntos de documentos analisados, concluir que quantativamente os termos relacionados com "aprender" surjam mais vezes.

No que respeita ao conjunto $A$, indica-se que "na nossa análise não nos parece muito evidente o uso de uma linguagem de aprendizagem em detrimento do uso da linguagem da educação." (Gomes \& Neves, 2008: 22). No caso do conjunto $B$, conclui-se que

a palavra 'educação' é claramente a que mais presente está nestes documentos (1004 ocorrências). Com ocorrências em torno de 500 encontramos três termos articulados com a temática dos documentos em análise - 'skills', 'competências' e 'competências-chave' — destacando-se, 
ainda, com um número de ocorrências semelhante, 'aprendizagem' (Alves \& Vicêncio, 2008: 24).

Com base apenas na análise quantitativa, com as limitações que lhe são inerentes, poderá revelar-se excessivo afirmar que a "linguagem da aprendizagem" substituiu a "linguagem da educação", ainda que, como sabemos, toda a questão educativa pareça ser, no âmbito das políticas educativas europeias, perspectivada sob a égide da aprendizagem ao longo da vida. Como se afirma num dos relatórios da análise documental, "a União Europeia ao referir-se ao processo de aquisição de conhecimentos, reconversão e actualização de competências, denomina-o de «aprendizagem ao longo da vida»" (Gomes \& Neves, 2008: 22).

Ora, a presença dominante da aprendizagem e da aprendizagem ao longo da vida, ainda que não identificável do ponto de vista lexical e quantitativo, encerra alguns riscos que vêm sendo identificados na reflexão crítica de diversos autores (ver, por exemplo, Canário, 2003; Lima, 2003) e que podem ser ilustrados pelas palavras de Biesta (2005: 64):

one way, therefore, to summarise my critique is to say that while the new language of learning has had a positive impact in some areas, it has proven to be a language very suitable for those who want to think of education strictly in economic terms, that is, as an exchange between a provider and a consumer.

De facto, relativamente às finalidades com que a aprendizagem ao longo da vida é implementada e defendida enquanto orientação estratégica da política educativa, a análise documental realizada permite suportar a hipótese de que a visão economicista da educação e das suas finalidades tem vindo a assumir uma preponderância significativa nas orientações estratégicas da política educativa europeia.

No caso do conjunto de documentos A refere-se a existência de

uma tendência para uma orientação mais economicista e mais vocacionada para o mercado de trabalho e para a competitividade (...). Portanto, ao nível dos aspectos ideológicos, conseguimos levantar algumas hipóteses que vão no sentido de uma orientação mais economicista camuflada por uma retórica que tenta evidenciar tendências para o desenvolvimento individual e social (Gomes \& Neves, 2008: 22).

No que respeita ao conjunto de documentos $B$ conclui-se que 
na análise dos documentos considerados, é globalmente notória a aceitação do pressuposto de que os níveis mais elevados de escolarização e qualificação favorecem a empregabilidade, entendendo-se que a implementação de estratégias de aprendizagem ao longo da vida é fundamental para assegurar o pleno emprego, bem como a qualidade e produtividade do trabalho (...) esta visão fortemente subjugada a objectivos económicos surge matizada com preocupações de cidadania, inclusão social e desenvolvimento pessoal (Alves \& Vicêncio, 2008: 29-30).

Um outra ideia-chave, quando se pretende entender os sentidos e significados da aprendizagem ao longo da vida, relaciona-se com o modo como é perspectivado o próprio processo de aprendizagem e como nele se articulam, de modo mais ou menos evidente, a diversidade existente de contextos de aprendizagem (os espaços) e as diferentes idades da vida (os tempos).

Os resultados da análise documental realizada apontam para a hipótese de que a aprendizagem ao longo da vida esteja a ser entendida, no quadro das orientações políticas estratégicas, de acordo com uma visão bastante escolarizada. Relativamente ao conjunto de documentos $B$ afirma-se que

as orientações estratégicas de aprendizagem ao longo da vida presentes dos documentos analisados parecem remeter, em grande medida, para os sistemas formais de educação e formação, designadamente os que se destinam a jovens adultos e aqueles que se vocacionam para a educação/formação inicial obrigatória (Alves \& Vicêncio, 2008: 31).

e nota-se também que são "quase inexistentes as referências às organizações aprendentes ou às cidades ou regiões aprendentes" (idem).

No mesmo sentido, aponta-se sobre o conjunto de documentos A que "por um lado, consideramos que há uma vontade política de envolver e dar sentido a todos os modos de educar e aprender, por outro lado, há uma dificuldade forte em conter a educação informal em mecanismos e espaços próprios e designáveis" (Gomes \& Neves, 2008: 28). Neste mesmo relatório assinala-se, complementarmente, que existem acepções divergentes nos documentos analisados em torno da educação e aprendizagem informais, encontrando-se expressões como "ensino informal" e "estabelecimento de ensino informal" que são em si mesmas contraditórias. Simultaneamente, destaca-se que "o reconhecimento e validação de competências e aprendizagens não-formais e informais são objectivos políticos não tão 
frequentes como a aquisição de competências e conhecimentos, o que leva a levantar a suspeita de que o principal objectivo é estimular a aquisição de conhecimentos e competências, mais do que reconhecê-los e validá-los" (Gomes \& Neves, 2008: 26).

Um outro indício da dificuldade em separar a aprendizagem ao longo da vida de uma visão escolarizada de educação e aprendizagem consiste na circunstância da análise dos dois conjuntos de documentos convergir na ideia de que as competências privilegiadas remetem, sobretudo, para áreas disciplinares e muito menos significativamente para conhecimentos e atitudes transversais a diferentes domínios. Este aspecto é particularmente bem ilustrado no caso do conjunto $B$, verificando-se que algumas das competências-chave identificadas $^{6}$ remetem para áreas disciplinares (ex: língua materna, línguas estrangeiras, matemática, ciência e tecnologia). Neste sentido, parece estar presente, de algum modo, na tipologia de competências-chave, uma lógica disciplinar e de adição de conhecimentos, aptidões e atitudes enquadrados em áreas disciplinares, que coexiste com uma lógica de competências-chave transversais a vários domínios disciplinares (mais visível, por exemplo, em "aprender a aprender" ou "competências sociais e cívicas") (Alves \& Vicêncio, 2008: 34-35).

Em articulação com o que vimos referindo, importa destacar alguns elementos referentes aos actores que são identificados como protagonistas da aprendizagem ao longo da vida. Na verdade, a análise de conteúdo do conjunto A permitiu considerar dois conjuntos categoriais: (1) designação genérica de sujeitos individuais ("cidadão", "indivíduos", "pessoas", "adultos", "jovens", "crianças", "idosos") e (2) designação específica de sujeitos de aprendizagem ("aprendente", "aluno/a", "estudante", "formando/a", "educando/a", "discente"). Verificou-se no balanço dos 12 documentos que, por um lado, o primeiro conjunto é muito mais frequente do que o segundo e, por outro lado, que os vocábulos "idosos" e "crianças" são menos frequentes nestes documentos (Gomes \& Neves, 2008). O primeiro aspecto é convergente com os slogans políticos da educação para todos e em todas as idades da vida, mas o segundo aspecto indicia uma maior preocupação com as dinâmicas de aprendizagem ao longo da vida protagonizadas por jovens e adultos (indivíduos em idade de actividade profissional) em detrimento de crianças e idosos. 
Em síntese, pode colocar-se a hipótese de que os sentidos e significados conferidos à aprendizagem ao longo da vida nos documentos analisados oscilam entre um entendimento que se encontra ainda próximo de uma visão restrita de aprendizagem e uma outra perspectiva que também valoriza os espaços não formais e informais de aprendizagem. Concomitantemente, constata-se que todos os indivíduos são protagonistas da aprendizagem ao longo da vida sendo dado particular relevo a jovens e adultos, ou seja, a população em idade activa, o que nos parece consistente com a ideia de que as orientações estratégicas das políticas educativas se regem, significativamente, por objectivos economicistas e profissionais.

\section{Dinâmicas de Aprendizagem ao Longo da Vida}

Com o objectivo genérico de antever de que modo as orientações políticas europeias de promoção da aprendizagem ao longo da vida estão sendo traduzidas em dinâmicas substantivas procurando, em particular, situar o caso português no panorama europeu, consideramos sucintamente alguns indicadores estatísticos disponibilizados por organismos europeus. Globalmente, importa sublinhar que a observação desses elementos estatísticos nos conduz a colocar a hipótese de que a motivação para aderir a dinâmicas de aprendizagem ao longo da vida tende a assumir expressões diversificadas em função do percurso prévio dos indivíduos e dos países no que respeita à educaçâo e à formação.

De facto, os dados obtidos no inquérito efectuado pelo CEDEFOP, em 2003, indicam que a proporção de pessoas que não se manifestam interessadas em aprender é particularmente elevada, por exemplo, no caso português (50\%), ao mesmo tempo que no nosso país também se verifica a tendência para menos indivíduos afirmarem aprender em diversos contextos da vida do que, nomeadamente, na Finlândia, Suécia ou Islândia. Ou seja, se em Portugal os diferentes indicadores de desempenho do sistema educativo são menos favoráveis por comparação com a média europeia, esta situação parece ter implicações nas dinâmicas de aprendizagem ao longo da vida dos cidadãos do nosso país.

Estas constatações são convergentes com os resultados de uma investigação que realizámos anteriormente, os quais contribuem para apoiar 
a ideia de que os indivíduos que atingem níveis de escolaridade mais elevados têm uma maior propensão para voltar a frequentar o sistema educativo ou para procurar acções de formação, ao mesmo tempo que mais frequentemente reconhecem as aprendizagens que realizaram em contextos informais (Alves, 2008). Ora, sabendo que a população portuguesa se distingue, no contexto europeu, por uma escolaridade média pouco elevada será de considerar a hipótese de que a adesão à aprendizagem ao longo da vida não seja particularmente significativa no país.

A observação de dados estatísticos disponibilizados pelo Eurostat permite observar tendências semelhantes ao que acabamos de afirmar, pois a aprendizagem ao longo da vida assume diferentes expressões nos vários países: abrange, no ano de 2006, 9,6\% da população dos 27 países da União Europeia $^{7}$, mas esse valor é de apenas $3,8 \%$ no caso português. De resto, com um valor idêntico ou inferior a Portugal encontramos a Hungria (também, $3,8 \%$ ) a Turquia (2\%), bem como a Grécia $(1,9 \%)$ e a Bulgária ou Roménia (cada um destes países com 1,3\%). No extremo oposto, países como o Reino Unido $(26,6 \%)$, a Finlândia $(23,1 \%)$ ou a Dinamarca $(29,2 \%)$ apresentam os valores mais elevados neste indicador.

A interpretação destes dados conduz à hipótese de que, aparentemente, as dinâmicas de aprendizagem ao longo da vida medidas por este indicador tendem a ser mais significativas em países nos quais os sistemas educativos se consolidaram cedo e onde a literacia e a escolaridade assumem valores mais favoráveis. Neste sentido, a diversidade de situações dos países perante a aprendizagem ao longo da vida é, de algum modo, marcada pelo modo como nesses países emergiram e se consolidaram os sistemas educativos.

Em síntese, a análise das dinâmicas de aprendizagem ao longo da vida em diversos grupos e nos diferentes países europeus indicia que, geralmente, aqueles que registam piores desempenhos em matéria de indicadores de escolaridade (taxas de sucesso e abandono por exemplo) são também aqueles que apresentam taxas de participação mais baixas na educação/formação de adultos. Aliás, como recorda Afonso (2005: 172), "tal como tem acontecido em relação à educação formal, também a educação informal e não-formal podem inscrever-se, quer em lógicas de reprodução e de regulação, quer em lógicas de mudança e de emancipação social". 
Ora, de acordo com a hipótese que apresentamos, as dinâmicas de aprendizagem ao longo da vida parecem poder significar uma reprodução das desigualdades existentes, entre países e entre grupos de indivíduos, quer na motivação para a aprendizagem quer no acesso às acções e sistemas de educação e formação. Nestas condições, consideramos necessário aprofundar melhor os contornos desta hipótese genérica, bem como não a esquecer aquando da promoção de dinâmicas de aprendizagem ao longo da vida, com o objectivo de não arriscar um agravamento das desigualdades já existentes entre países e entre indivíduos.

\section{Nota Conclusiva}

O objectivo do presente artigo é o de reflectir sobre a ideia de aprendizagem ao longo da vida, questionando aquilo que nela constitui (ou não) novidade quer no plano dos sentidos e significados, quer nas alterações que introduz (ou não) por um lado, nas orientações estratégicas subjacentes às políticas educativas e, por outro lado, nos processos de educação e formação. Assim sendo, gostaríamos de sintetizar alguns elementos relativos a este objectivo, os quais foram alcançados através dos contributos teóricos e empíricos de diferentes naturezas mobilizados ao longo do texto.

Globalmente, concluímos que existem poucos elementos portadores de 'novidade' em toda esta centralidade crescente da ideia de aprendizagem ao longo de vida. Do ponto de vista teórico e conceptual, esta ideia - embora não necessariamente com esta designação - tem estado presente no pensamento sobre educação de diversos autores ao longo dos tempos, bem como na reflexão que acontece nos organismos internacionais há já várias décadas. Do ponto de vista substantivo, a aprendizagem confunde-se com a própria existência humana e, neste sentido, teve sempre lugar ao longo da vida e em diferentes espaços da nossa existência. Porém, do ponto de vista das práticas e sistemas educativos, $\mathrm{o}$ (re)conhecimento da abrangência da ideia de aprendizagem ao longo da vida dá origem a desafios relativamente ao seu modo de funcionamento que podem encerrar alguma novidade.

Do ponto de vista das políticas, se é verdade que a apologia da aprendizagem ao longo da vida como elemento central das orientações estratégicas constitui uma novidade, constata-se igualmente que tal situação 
obriga a retomar debates que desde sempre atravessam a educação sobre as suas finalidades nos planos da economia/emprego, sociedade/coesão social ou indivíduo/construção da pessoa.

A observação dos estreitos laços existentes entre a motivação e adesão a dinâmicas de aprendizagem ao longo da vida e o maior ou menor sucesso anterior dos percursos escolares, a nível individual, ou dos processos de desenvolvimento e consolidação de sistemas educativos, a nível societal, conduzem a colocar a hipótese de que essas dinâmicas contribuam para reproduzir velhas desigualdades. Isto, no sentido em que aqueles (indivíduos ou sociedades) que mais aderem a dinâmicas de aprendizagem ao longo da vida tendem a ser, aparentemente, também os que conheceram mais sucesso no que respeita aos processos de escolarização. Se tal se verificar, a centralidade da aprendizagem ao longo de vida não tornará as políticas educativas mais geradoras de equidade, pois continuarão a acentuar as desigualdades já existentes.

Nestas condições, consideramos particularmente relevante, em trajectos de investigação futuros, aprofundar o modo como as orientações subjacentes às políticas educativas europeias vêm sendo entendidas e vêm influenciando as acções e decisões de países, instituições e indivíduos em matéria de educação e formação. Esta opção é especialmente pertinente por duas razões: por nos parecer tratarem-se de níveis de análise carentes de investigação e pelo facto de partilhamos da perspectiva segundo a qual a política (educativa, neste caso) é um resultado contingente e processual das interacções entre actores, instituições, discursos e acontecimentos (Lindblad, Ozga, Zambeta, 2002).

\section{Notas}

1 Este artigo reúne resultados de um projecto de investigação em equipa financiado pela FCT/MCTES com o título "Educação e Desenvolvimento Humano no contexto da União Europeia: Análise comparativa das Políticas Educativas Europeias à luz do paradigma da Aprendizagem ao Longo da Vida" (referência PTDC/CED/60425/2004) que decorreu entre 2007 e 2009.

2 Nestes contextos informais a aprendizagem pode ser intencional, mas é na maioria dos casos não intencional e pode ser referenciada como aprendizagem experencial (Tuschlung \& Engemann, 2006). 
3 Para Biesta (2006) existem diferenças entre a visão da UE e a visão de um outro organismo internacional - a OCDE - na qual é menos marcado o reducionismo económico que caracteriza a retórica europeia.

4 Consideramos os documentos "textos políticos" no sentido que lhes é conferido por Lingard e Ozga (2006) enquanto textos que procuram enquadrar e mudar as práticas educativas ou ainda enquanto meios de difusão de uma determinada mensagem política.

5 Ver, no anexo 1, a nota metodológica em que se explicitam os critérios e procedimentos seguidos na análise documental.

6 Para uma listagem das competências-chave identificadas nestes documentos pode consultar-se o anexo 2.

7 Os dados que se apresentam são disponibilizados pelo Eurostat e referem-se à percentagem de população adulta entre os 25 e os 64 anos que afirmou ter participado em acções de educação e formação nas 4 semanas anteriores ao survey.

\section{Referências}

AFONSO, Almerindo (2005). A Sociologia da Educação em Portugal. Elementos para a configuração do «estado da arte». In A. Teodoro \& C. Torres (Orgs.), Educação Crítica e Utopia - Perspectivas para o século XXI. Cortez Editora: São Paulo.

ALVES, Mariana (2008). Contributos para pensar a regulação entre Educação, Trabalho e Emprego. In M. Alves et al., Universidade e Formação ao Longo da Vida. Oeiras: Celta Editores (no prelo).

ALVES, Mariana \& VICÊNCIO, Ana Margarida (2008). Relatório de Análise de Documentos da União Europeia sobre "Competências-chave da Aprendizagem ao Longo da Vida", Projecto PEE, UIED - FCT/UNL, documento policopiado.

ALVES, Mariana (2007). A inserção profissional de diplomados de ensino superior numa perspectiva educativa: o caso da Faculdade de Ciências e Tecnologia, Lisboa, Fundação Calouste Gulbenkian/Fundação para a Ciência e a Tecnologia/MCTES.

BARDIN, Laurence (2004). Análise de Conteúdo. Lisboa: Edições Setenta.

BECK, Ulrich; GIDDENS, Anthony \& LASH, Scott (2000). Modernização Reflexiva: Política, Tradição e Estética no Mundo Moderno. Oeiras: Celta Editores.

BIESTA, Gert (2006). What's the point of Lifelong Learning if LifeLong Learning has no point? On the Democratic Deficit of Policies for LifeLong Learning. European Educational Research Journal, volume 5, numbers _.

BIESTA, Gert (2005). Against learning. Reclaiming a language of education in a time of learning. Nordisk Pedagogik, 25, pp. 54-66.

CANÁRIO, Rui (2003). A aprendizagem ao longo da vida. Análise crítica de um conceito e de uma política. In R. Canário (org.), Formação e Situações de Trabalho. Porto: Porto Editora. 
FERNÁNDEZ, Florentino Sanz (2006). As Raízes Históricas dos Modelos Actuais de Educação de Pessoas Adultas. Lisboa: Edições Educa.

FREDRIKSSON, Ulf (2003). Changes of Education Policies within the European Union in the Light of Globalisation. European Educational Research, volume 2, number 4.

GOMES, Elisabete \& NEVES, Cláudia (2008). Relatório de Análise de Documentos de Referência da União Europeia para as Políticas Educativas, Projecto PEE, UIED - FCT/UNL, documento policopiado.

JARVIS, Peter (2007). Globalisation, Lifelong Learning and the Learning Society. Sociological Perspectives. London \& New York: Routledge.

LIMA, Licínio (2003). Formação e aprendizagem ao longo da vida: entre a mão direita e a mão esquerda de Miró. In AAVV, Cruzamento de Saberes e Aprendizagens Sustentáveis. Lisboa: Fundação Calouste Gulbenkian.

LINDBAND, Sverker; OZGA, Jenny \& ZAMBETA, Evie (2002). Changing forms of Educational Governance in Europe. European Research Journal, volume 1, number 4.

NÓVOA, António (2005). Les états de la politique dans l'espace européen de l'éducation. In M. Lawn \& A. Nóvoa (eds.), L'Europe Réinventée - regards critiques sur l'espace européen de l'éducation. Paris: L'Harmattan.

PERRENOUD, Philippe (1995). Ofício do Aluno e Sentido do Trabalho Escolar. Porto: Porto Editora.

PIRES, Ana Oliveira (2005). Educação e Formação ao Longo da Vida: Análise Crítica de Sistemas e Dispositivos de Reconhecimento e Validação de Aprendizagens e de Competências. Lisboa: Fundação Calouste Gulbenkian.

TUSCHLUNG, Anna \& ENGEMANN, Christoph (2006). From Education to Lifelong Learning: the emerging regime of learning in the European Union. Educational Philosophy and Theory, vol. 38, no 4 .

VALA, Jorge (1986). A análise de conteúdo. In A. Santos Silva \& J. M. Pinto (Eds.), Metodologia das Ciências Sociais. Porto: Edições Afrontamento. 


\title{
LIFELONG LEARNING - BETWEEN NOVELTY AND THE REPRODUCTION OF OLD INEQUALITIES
}

\begin{abstract}
Lifelong Learning has been a central issue, namely within political discourses from the European Commission, and it conveys the idea that this is a new strategy within Education that will allow us to overcome many old problems that have been facing the development of the educational and training systems. In this article we intend to discuss to what extent is lifelong learning a novelty within the educational field. To meet that purpose we consider three inter-related dimensions in our analysis: (1) the meanings and understandings of the idea of lifelong learning, the educational changes occurring within the paradigm of lifelong learning in what concerns (2) educational policy and (3) educational and training processes. We also address the debate on the dynamics of lifelong learning and the ways it contributes to the persistence (or diminishing) of inequalities that have been underlying the development of educational systems.
\end{abstract}

Keywords

European Educational Policies; Inequalities; Learning

\section{ÉDUCATION TOUT AU LONG DE LA VIE - ENTRE LA NOVEAUTÉ ET LA REPRODUCTION DES VIEUX INEGALITÉS}

\section{Résumé}

Lifelong learning est manintenant un mot-clé dans les discourses politiques, en particuliére ces de la Commission Européenne, et le suject d'une nouvelle stratégie en éducation sur laquelle on souhaite être capable de résoudre des vieux problems dans le developpement des systèmes d'éducation et formation. Dans ce texte nous prétendons reflechir sur l'idée de lifelong learning en s'interrogeant sur son caráctere de noveauté. Cette réflexion se 
développe en trois dimensions articulés: (1) les signifiées de l'idée de lifelong learning, les changements educatifs associées au lifelong learning dans les thématiques (2) de la politique et stratégie educative et (3) des processus educatifs. Nous analysons aussi dans ce texte le débat au tour de cette dynamique lié au lifelong leraning et la persistence (ou reduction) des inégalités sous-jacents au développement des systémes d'éducation et formation.

Mots-clé

Politiques Éducatives Européennes; Inégalités; Apprentissage

Recebido em Setembro/2008

Aceite para publicação em Novembro/2009 


\section{ANEXOS}

\section{Anexo 1 - Metodologia da análise documental}

Neste artigo mobilizamos os resultados de duas operações empíricas de análise documental que incidiram sobre dois conjuntos distintos de documentos da União Europeia, todos eles produzidos a partir do ano 2000. Note-se que a relevância deste marco temporal se justifica, simultaneamente, pelo facto de a nossa intenção principal ser a de compreender a actual estratégia política da União Europeia para o domínio educativo, bem como pela circunstância de ser a partir daquele ano que se intensifica o papel e influência das entidades europeias no sector educativo.

Um dos conjuntos de documentos analisados (o conjunto A) é constituído por 12 documentos, os quais foram identificados, após um trabalho de análise exploratória, como aqueles que dizem respeito ao quadro de referência político para os Programas "Educação e Formação 2010" e "Aprendizagem ao Longo da Vida 2007-2013" que reunem os planos, iniciativas e acções previstas pela União Europeia para o sector educativo. Foram seleccionados estes documentos de enquadramento político genérico (memorandos, decisões, relatórios, comunicações,...) porque nos interessava compreender aspectos ideológicos e conceptuais subjacentes às orientações gerais, sendo que não considerámos, portanto, documentos mais específicos centrados em domínios particulares como as TIC ou as Línguas entre tantos outros.

Os procedimentos de análise de conteúdo destes 12 documentos desdobraram-se em duas fases: a primeira corresponde a uma análise de conteúdo qualitativa e temática, orientada por uma técnica de análise categorial (Bardin, 2004) em que as categorias identificadas decorreram do enquadramento e dos objectivos gerais do projecto de investigação; a segunda é uma análise de conteúdo quantitativa e lexical destinada a caracterizar os documentos também pela ocorrência e frequência das palavras utilizadas na construção do discurso. Em nosso entender, o uso combinado de métodos qualitativos e quantitativos permite enriquecer os níveis de interpretação em documentos com a extensão e diversidade que este corpus apresenta.

$\mathrm{O}$ outro conjunto de documentos analisados corresponde a um corpus (o conjunto B) composto por 8 documentos. Neste caso, e para complementar o conjunto anterior, optámos por focar a nossa atenção num conjunto de documentos que dão conta da actividade de um grupo de trabalho centrado nas competências-chave para a aprendizagem ao longo da vida, o qual está na origem da Recomendação do Parlamento Europeu e do Conselho sobre as Competências Essenciais para a Aprendizagem ao Longo da Vida publicada no Jornal Oficial da União Europeia, em Dezembro de 2006. Na verdade, tendo em conta que é nosso objectivo compreender os sentidos e significados da aprendizagem ao longo da vida, a análise dos documentos que sublinham quais as competências-chave essenciais dessa mesma aprendizagem ao longo da vida pareceu-nos fundamental como complemento da análise do conjunto $A$.

A análise de conteúdo dos documentos do conjunto B foi concretizada procurando analisar sistematicamente os mesmos, de modo a favorecer a realização de inferências que permitam passar da descrição à interpretação atribuindo sentido às características do material que foram sendo levantadas, enumeradas e organizadas (Bardin, 1977 e Vala, 1986). No difícil equilíbrio entre o respeito dos sentidos conferidos aos textos em análise pelos seus autores e a necessidade de operacionalizar 
procedimentos que permitissem efectuar inferências pertinentes para as questões de investigação que orientam o nosso trabalho, realizou-se a análise de conteúdo que se desdobrou nas etapas seguintes.

A primeira etapa consistiu numa "leitura flutuante", após o que se optou, numa segunda etapa, pela realização de fichas-síntese dos documentos de acordo como uma grelha de categorias que visava essencialmente sistematizar os conteúdos de cada documento. Numa terceira etapa, a análise destas fichas-síntese de documentos conduziu a que optássemos pela realização de uma análise comparativa das diversas competências-chave identificadas, uma vez que se pode observar que as mesmas foram objecto de algumas reformulações e/ou precisões ao longo dos documentos que foram objecto da nossa análise. Em paralelo considerou-se relevante a realização de uma análise quantitativa de termos e/ou expressões recorrentemente utilizadas nos documentos, enquanto modo de explicitar algumas questões em análise. A ideia subjacente é a de que "a análise de ocorrências visa determinar o interesse da fonte por diferentes objectos ou conteúdos" (Vala, 1986: 118).

Importa explicitar que, como é evidente, os resultados alcançados com a análise de conteúdo realizada não pretendem ser representativos de toda a documentação produzida na União Europeia para enquadramento das políticas educativas.

\section{Listagem do corpus documental}

Conjunto A:

1 Memorando sobre aprendizagem ao longo da vida - documento de trabalho da Comissão, Outubro 2000

2 Relatório do Conselho "Educação" sobre os objectivos futuros concretos dos sistemas de educação e de formação, Fevereiro 2001

3 Comunicação da Comissão: Tornar o espaço europeu de aprendizagem ao longo da vida uma realidade, Novembro 2001

4 Programa de trabalho pormenorizado relativo ao seguimento dos objectivos dos sistemas de ensino e de formação na Europa, Conselho Educação e Comissão, Fevereiro 2002

5 Resolução do Conselho Europeu de Junho 2002 sobre a ALV, Junho 2002

6 Comunicação da comissão: investir eficazmente na educação e na formação - um imperativo para a Europa, Janeiro 2003

7 Educação e Formação para 2010: a urgência das reformas necessárias para o sucesso da estratégia de Lisboa - relatório intercalar conjunto sobre a realização do programa de trabalho pormenorizado relativo ao seguimento dos objectivos dos sistemas de ensino e formação na Europa, Conselho Educação e Comissão, Fevereiro 2004

8 Decisão no 791/2004/CE do Parlamento Europeu e do Conselho que institui um programa de acção comunitário para a promoção de organismos activos no plano europeu e o apoio a actividades pontuais no domínio da educação e da formação, Abril 2004 
9 Modernizar a educação e a formação: um contributo vital para a prosperidade e a coesão social na Europa - Relatório Intercalar conjunto do Conselho Europeu e da Comissão, Fevereiro 2006

10 Comunicação da comissão sobre eficiência e equidade nos sistemas de educação e de formação, Setembro 2006

11 Decisão no 1720/2006/CE do Parlamento Europeu e do Conselho que estabelece um programa de acção no domínio da aprendizagem ao longo da vida, Novembro 2006

12 Conclusões do conselho e dos representantes dos governos dos estados-membros reunidos no conselho sobre a eficiência e equidade dos sistemas de educação e de formação, Dezembro 2006

Conjunto B:

1 Implementations of "Education and Traning 2010" Work Programme Working group "Basic Skills, entrepreneurship and foreign languages" Progress Report, Novembro 2003

2 Implementations of "Education and Traning 2010" Work Programme Working group "Key Competences" Progress Report, Novembro 2004

3 Implementations of "Education and Traning 2010" Work Programme Working group "Key Competences", Analysis of the Mapping of Key Competency Frameworks, Novembro 2004

4 Implementations of "Education and Traning 2010" Work Programme Working group "Key Competences", Key Competences for Lifelong Learning - a European Reference Framework, Novembro de 2004

5 Implementations of "Education and Traning 2010" Work Programme Focus Group On Key Competences Report, Junho 2005

6 Proposta de Recomendação do Parlamento Europeu e do Conselho das competências essenciais para a aprendizagem ao longo da vida, Comissão Europeia das Comunidades, Novembro 2005

7 Parecer do Comité das Regiões sobre a Proposta de Recomendação do Parlamento Europeu e do Conselho sobre as competências essenciais para a aprendizagem ao longo da vida, Junho 2006

8 Recomendação do Parlamento Europeu e do Conselho de 18 de Dezembro de 2006 sobre as competências essenciais para a aprendizagem ao longo da vida. 


\section{Anexo 2}

\begin{tabular}{|c|c|c|}
\hline $\begin{array}{l}\text { Designação Inicial da } \\
\text { Competência Chave(no } \\
\text { documento } 1,2003)\end{array}$ & $\begin{array}{l}\text { Designações Intermédia } \\
\text { da Competência-Chave }\end{array}$ & $\begin{array}{l}\text { Designação Final da } \\
\text { Competência Chave (no } \\
\text { documento } 8,2006 \text { ) }\end{array}$ \\
\hline $\begin{array}{l}\text { 1- Comunicação em Língua } \\
\text { Materna }\end{array}$ & - & $\begin{array}{l}1 \text { - Comunicação na Língua } \\
\text { Materna }\end{array}$ \\
\hline $\begin{array}{l}\text { 2. Comunicação em Línguas } \\
\text { Estrangeiras }\end{array}$ & - & $\begin{array}{l}2 \text { - Comunicação em Línguas } \\
\text { Estrangeiras }\end{array}$ \\
\hline 3.1 - Literacia Matemática & 3.1 - Literacia Matemática & \multirow{2}{*}{$\begin{array}{l}\text { 3- Competência Matemática e } \\
\text { Competências Básicas em } \\
\text { Ciência e Tecnologia (desde } \\
\text { documento 5, Junho de 2006) }\end{array}$} \\
\hline 3.2-Ciência e Tecnologia & $\begin{array}{l}\text { 3.2 - Competência em Ciência e } \\
\text { Tecnologia (documento } 4 \text {, } \\
\text { Novembro de 2004) }\end{array}$ & \\
\hline $4-\mathrm{TIC}$ & - & $\begin{array}{l}\text { 4-Competência Digital (desde } \\
\text { documento 4, Novembro de } \\
\text { 2004) }\end{array}$ \\
\hline 5-Aprender a Aprender & - & 5-Aprender a Aprender \\
\hline $\begin{array}{l}6.1 \text { - Competências } \\
\text { interpessoais, interculturais e } \\
\text { sociais }\end{array}$ & \multirow{3}{*}{$\begin{array}{l}\text { 6. Competências interpessoais, } \\
\text { interculturais e sociais e } \\
\text { competências cívicas } \\
\text { (documento 5, Junho de 2006). }\end{array}$} & \multirow[t]{2}{*}{$\begin{array}{l}6 \text { - Competências Sociais e } \\
\text { Cívicas (desde documento } 8 \text {, } \\
\text { 2006) }\end{array}$} \\
\hline 6.2 - Competências Cívicas & & \\
\hline 7 - Empreendedorismo & & $\begin{array}{l}7 \text { - Espiríto de iniciativa e } \\
\text { espírito empresarial (desde } \\
\text { documento } 8,2006 \text { ) }\end{array}$ \\
\hline 8 - Expressão Cultural & - & $\begin{array}{l}8 \text { - Sensibilidade e expressão } \\
\text { culturais (desde documento } 8 \text {, } \\
\text { 2006) }\end{array}$ \\
\hline
\end{tabular}

Designações atribuídas às oito competências-chave ao longo dos documentos analisados 